\title{
Effect of organic acids and mannanoligosaccharide on excretion of Salmonella typhimurium in experimentally infected growing pigs
}

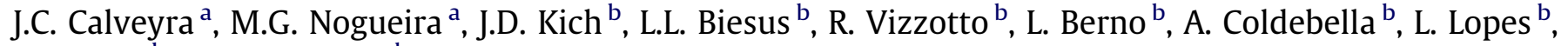 \\ N. Morés ${ }^{\mathrm{b}}$, G.J.M.M. Lima ${ }^{\mathrm{b}}$, M. Cardoso ${ }^{\mathrm{a}, *}$ \\ a Faculdade de Veterinária, Universidade Federal do Rio Grande do Sul, Brazil \\ ${ }^{\mathrm{b}}$ Embrapa Suínos e Aves, Santa Catarina, Brazil
}

\section{A R T I C L E I N F O}

\section{Article history:}

Received 24 August 2010

Accepted 22 August 2011

Available online $\mathrm{xxxx}$

\section{Keywords:}

Swine

Salmonella

Organic acids

Mannanoligosaccharide

\begin{abstract}
A B S T R A C T
The effect of organic acids and mannanoligosaccharide addition to the diet was assessed in pigs orally inoculated with Salmonella typhimurium. Forty-six growers were distributed among four treatments: Basal Diet (BD); BD + encapsulated organic acids; BD + free organic acids; BD + mannanoligosaccharide. Seroconversion was monitored, and feces and tissue samples were tested for Salmonella isolation. No treatment prevented the carrier state, but a tendency of lower fecal excretion was observed in the group treated with mannanoligosaccharide.
\end{abstract}

(c) 2011 Elsevier Ltd. All rights reserved.
Dietary additives have been proposed as alternative tools to be adopted for reduction of Salmonella carrier pigs (Visscher et al., 2005; Creus et al., 2007; Papenbrock et al., 2009.). Therefore, the aim of this study was to evaluate the effect of either organic acid or mannanoligosaccharide dietary addition on Salmonella typhimurium carriage and fecal shedding in challenged growers.

The experiment was conducted in a randomized complete block design divided in two consecutive periods. Each block included all treatments, which were composed of six animals each, housed in separated pens in the same room at the biosafety facilities of Embrapa Swine and Poultry Research Center, Brazil. Forty-eight Salmonella-negative pigs (43-day-old, $11.39 \pm 1.6 \mathrm{~kg}$ body weight) were allotted to one of the following treatments: a basal diet without additives (CON, control), and basal diets added with a blend of encapsulated organic acid (EOA, fumaric acid $20 \%$, citric acid $10 \%$, malic acid $10 \%$, phosphoric acid $10 \%$; Tetracid $^{\circledR}$ TM-500, Jefo Nutrition Inc.), or a blend of short chain free organic acids (SOA, formic acid $26 \%$, propionic acid $10 \%$, plant fatty acids $18 \%$; Selacid Green Growth $^{\circledR}$ Selko Latin America Ltda.) or prebiotic (MOS, mannanoligosaccharide $12 \%$, Bio-Mos ${ }^{\circledR}$ Alltech Biotechnology Ltda.). The additives were mixed with the basal diet in a proportion of $2 \mathrm{~kg} /$ ton of feed, as recommended by the manufacturers. Pigs had ad libitum access to water and feed throughout the experiment.

\footnotetext{
* Corresponding author. Address: Faculdade de Veterinária, UFRGS, Av. Bento Gonçalves 9090, Porto Alegre, RS 90540-000, Brazil. Tel.: +55 513308 6123; fax: +555133087305.

E-mail address: mcardoso@ufrgs.br (M. Cardoso).
}

The protocol was approved by the Research Ethics Committee of Universidade Federal do Rio Grande do Sul (number 2007-962).

Two weeks after housing, pigs were orally challenged (day 0 post-inoculation, $0 \mathrm{PI}$ ) with a $10 \mathrm{~mL}$-dose of a S. typhimurium suspension (106 colony forming units/mL). Two pigs from the control group died due to Streptococcus suis meningitis before the inoculation and were not replaced. Blood and fecal samples were collected on days 14 and 7 before inoculation and on days $0,3,7,14,21,28$ PI. On day 35PI, animals were weighed, euthanized, and samples of blood and organs were collected. Samples were submitted to the ISO6579 Salmonella isolation protocol. Fecal samples were tested following the ISO6579 Annex D (ISO, 2007). Quantification of Salmonella was performed in feces samples by the Most Probable Number method, according to BAM (2003). Serum samples were tested by an indirect IgG-ELISA assay based on somatic antigen 1 , 4,5 and 12 of Salmonella (Kich et al., 2007). Results were analyzed by the MIXED or the FREQ procedures of SAS (2002).

All treatment groups were infected, as evidenced by the isolation of Salmonella and by the seroconversion. The mean pig live weight increased in the four groups from $11.39( \pm 1.6)$ on the day of housing to $52.11( \pm 5.5)$ on day 35PI. Seroconversion started on day 7PI, and IgG titles increased significantly $(P<0.05)$ until day 35PI in all groups.

The frequency of Salmonella excretion varied from 100\% (10/10) on day 7PI in the control group to $25 \%(3 / 12)$ on day $28 \mathrm{PI}$ in the MOS group. No statistical difference was observed between groups throughout the experiment (Table 1). Results of Salmonella quantification showed interaction between treatment and 


\section{Table 1}

Frequencies of Salmonella fecal excretion in pigs fed with a basal diet (CON) or with a diet added of encapsulated organic acids (EOA), non-encapsulated organic acids (SOA) or mannanoligosaccharide (MOS), between days 3 and 28 after oral inoculation of Salmonella Typhimurium (DPI).

\begin{tabular}{rrrrll}
\hline DPI & CON $(n=10)$ & EOA $(n=12)$ & SOA $(n=12)$ & MOS $(n=12)$ & $P^{*}$ \\
\hline $\mathbf{3}$ & 7 & 11 & 10 & 10 & 0.6599 \\
$\mathbf{7}$ & 10 & 10 & 8 & 7 & 0.1136 \\
$\mathbf{1 4}$ & 8 & 7 & 6 & 5 & 0.3482 \\
$\mathbf{2 1}$ & 7 & 7 & 10 & 5 & 0.1804 \\
$\mathbf{2 8}$ & 7 & 5 & 6 & 3 & 0.1976 \\
\hline
\end{tabular}

* $P$-value of Fisher's Exact Test by the FREQ procedure of SAS.

\section{Table 2}

Quantification of Salmonella $\left(\log _{10} \mathrm{ufc}^{-1}\right.$ ) in fecal samples from pigs fed a basal diet (CON) or a diet added of encapsulated organic acids (EOA), non-encapsulated organic acids (SOA) or mannanoligosaccharide (MOS), between days 3 and 28 after oral inoculation of Salmonella Typhimurium (DPI).

\begin{tabular}{rlllll}
\hline DPI & CON & EOA & SOA & MOS & $P^{*}$ \\
\hline $\mathbf{3}$ & $0.61 \pm 0.31 \mathbf{B a}$ & $5.75 \pm 1.37 \mathbf{A c}$ & $4.39 \pm 1.20 \mathbf{A b}, \mathbf{c}$ & $1.99 \pm 0.83 \mathbf{a}, \mathbf{b}$ & 0.0019 \\
$\mathbf{7}$ & $4.66 \pm 1.07 \mathbf{A}$ & $3.01 \pm 0.81 \mathbf{B}$ & $1.93 \pm 0.78 \mathbf{A B}$ & $2.05 \pm 0.94$ & 0.1671 \\
$\mathbf{1 4}$ & $1.61 \pm 0.71 \mathbf{B}$ & $2.06 \pm 0.77 \mathbf{B C}$ & $0.60 \pm 0.28 \mathbf{B}$ & $0.77 \pm 0.53$ & 0.2148 \\
$\mathbf{2 1}$ & $0.57 \pm 0.20 \mathbf{B}$ & $1.05 \pm 0.34 \mathbf{C D}$ & $1.46 \pm 0.40 \mathbf{B}$ & $0.64 \pm 0.33$ & 0.1143 \\
$\mathbf{2 8}$ & $0.99 \pm 0.29 \mathbf{B a}$ & $0.64 \pm 0.24 \mathbf{D a}$ & $0.91 \pm 0.31 \mathbf{B a}$ & $0.23 \pm 0.12 \mathbf{b}$ & 0.0015 \\
$\mathbf{P}$ & 0.029 & $<0.01$ & 0.0033 & 0.064 & \\
\hline
\end{tabular}

Means followed by different lowercase letters (a, b, c) in the same line are different by $t$-test $(P<0.05)$.

Means followed by different capital letters (A, B, C, D) in the same column are different by $t$-test $(P<0.05)$.

${ }^{*} P$-value of $\mathrm{F}$ test by the MIXED procedure of SAS for repeated measures.

Day-post-inoculation (DPI, $\mathrm{P}=0.0056)$. Three groups (CON, EOA, SOA) presented an excretion peak of Salmonella after day 3PI, followed by a gradual decrease in fecal excretion until day 28PI (Table 2 ). The MOS group showed a trend of low excretion throughout the experiment, and on day 28PI had significantly less Salmonella in feces than the other groups.

Salmonella was isolated from various tissue samples in all groups, with a frequency ranging from $16.7 \%$ (liver from SOA and MOS) to $90 \%$ (lung from CON). Samples of cecum $(67.3 \%$ ) and lymph node (52.9\%) were Salmonella-positive, and there was no statistical difference in the number of intestinal carriers between groups. Besides the fecal-oral route, invasion through the respiratory tract has been demonstrated (Oliveira et al., 2006), and may have also occurred in our study, since tonsil (84.58\%) and lung (69.6\%) samples presented the highest rates of isolation. These results may raise the hypothesis that additives acting in the gastrointestinal tract will not be able to completely prevent the infection of the Salmonella-exposed pigs.

Organic acids have been extensively used due to their beneficial effect on the performance of reared pigs and improvement of gut health (Walsh et al., 2007). Addition of organic acids (0.4-0.9\% in-feed) has also been tested in weaned (Papenbrock et al., 2005; Taube et al., 2009) and market-age pig herds (Creus et al., 2007) to reduce the number of Salmonella-shedders. In spite of controlling Salmonella excretion, a substantial addition of acids to the diet may result in decrease of palatability, leading to depression of feed intake (Walsh et al., 2007). Thus, we tested organic acids in a concentration $(0.1 \%$ in-feed) successfully used to increase growth performance in pigs. However, the low acid concentration will apparently not be sufficient to decrease Salmonella shedding rates.

A tendency towards a lower fecal number of Salmonella was observed in the group fed on diets with added MOS. The action mechanism of probiotic compounds is related to the stimulation of fermentative activity in the gut, leading to a beneficial change in the intestinal flora and to interference with Salmonella colonization (Martín-Peláez et al., 2010). These combined effects might have reduced the Salmonella shedding rate in our study. Therefore, the effect of mannanoligosaccharide treatment of carrier pigs upon the infection rates in sentinel pigs deserves further investigation.

\section{Conflict of interest statement}

None declared.

\section{Acknowledgements}

This project was supported by Embrapa-Macroprograma II (Process number 02.06.06.004.0000) and Conselho Nacional de Pesquisa (J. Calveyra scholarship).

\section{References}

BAM, Bacteriological Analytical Manual, 2003. Available at: (http:/ www.fda.com.org). Appendix 2: Most Probable Number Determination from Serial Dilutions, 9th edition.

Creus, E., Pérez, J.F., Peralta, B., Boucells, F., Matell, E., 2007. Effect of acidified feed on the prevalence of Salmonella in market-age pigs. Zoonoses and Public Health $54,314-319$.

ISO. International Organization for Standardization. Available at: (http:// www.iso.org) ISO 6579. Microbiology of food and animal feeding stuff. Annex D: Detection of Salmonella sp in animal faeces and environmental samples from primary stage, 2007.

Kich, J.D., Schwarz, P., Silva, L.E., Coldebella, A.R.V., Cardoso, M., 2007. Development and application of an enzyme-linked immunosorbent assay to detect antibodies against prevalent Salmonella serovars in swine in southern Brazil. Journal of Veterinary Diagnostic Investigation 19, 510-517.

Martín-Peláez, S., Costabile, A., Hoyles, L., Rastall, R.A., Gibson, C.R., La Ragione, R.M. Woodard, M.J., Mateu, E., Martín-Orúe, S.M., 2010. Evaluation of the inclusion of a mixture of organic acids or lactulose into the feed of pigs experimentally challenged with Salmonella Typhimurium. Veterinary Microbiology 142, 337345.

Oliveira, C.B., Carvalho, L.F., Garcia, T.B., 2006. Experimental airbone transmission of Salmonella Agona and Salmonella Typhimurium in weaned pigs. Epidemiology and Infection 134, 199-209.

Papenbrock, S., Stemme, K., Amtsberg, G., Verspohl, J., Kamphues, J., 2005. Investigations on prophylactic effects of coarse feed structure and/or potassium diformate on the microflora in the digestive tract of weaned piglets experimentally infected with Salmonella Derby. Journal of Animal Physiology and Animal Nutrition 89, 84-87.

SAS INSTITUTE INC. System for Microsoft Windows: release 9.1.3. Cary: SAS Institute Inc., 2002-2003. 1 CD-ROM.

Taube, V.A., Neus, M.E., Hassan, Y., Verspohl, J., Beuerbach, M., Kamphues, J., 2009 Effects of dietary additives (potassium diformate/organic acids) as well as influences of grinding intensity (coarse/fine) of diets for weaned piglets experimentally infected with Salmonella Derby or Escherichia coli. Journal of Animal Physiology and Animal Nutrition 93, 350-358.

Visscher, C.F., Winter, P., Verspohl, J., Stratmann-Selke, J., Upmann, M., Beyerbach, M., Kamphues, J., 2009. Effect of feed particle size at dietary presence of added organic acids on caecal parameters and the prevalence of Salmonella in fattening pigs on farm and at slaughter. Journal of Animal Physiology and Animal Nutrition 93, 423-430.

Walsh, M.C., Sholly, D.M., Hinson, R.B., Saddoris, K.L., Sutton, A.C., Radcliff, J.S., Odgaard, R., Murphy, J., Richert, B.T., 2007. Effects of water and diet acidification with and without antibiotics on weanling pig growth and microbial shedding. Journal of Animal Science 85, 1799-1809. 